\title{
The Production of Polyethylene Terephthalate Nanofibers by Electrospinning with Minimum Amount of Trifluoroacetic Acid
}

\author{
Attila Gergely* \\ Department of Mechanical Engineering, Faculty of Technical and Human Sciences, Sapientia Hungarian University of Transylvania, \\ Romania \\ *Corresponding author: Attila Gergely, Department of Mechanical Engineering, Faculty of Technical and Human Sciences, Sapientia \\ Hungarian University of Transylvania, Corunca, 1C, 540485, Targu Mures, Romania
}

\begin{abstract}
ARTICLE INFO
Received: 慧 July 21, 2020

Published: 幽 August 07, 2020

Citation: Attila Gergely. The Production of Polyethylene Terephthalate Nanofibers by Electrospinning with Minimum Amount of Trifluoroacetic Acid. Biomed J Sci \& Tech

\section{ABSTRACT}

Polyethylene terephthalate fiber mats were prepared by solution electrospinning with average fiber diameters ranging from $150 \mathrm{~nm}$ to $500 \mathrm{~nm}$ depending on the processing conditions. The minimum amount of trifluoracetic acid was determined at which the electrospinning process generates randomly oriented and smooth surfaced fibers. A three factorial Box-Behnken experimental design was used to determine the effect of the processing parameters on the resulting fiber diameter. It was found that the dichloromethane: trifluoroacetic acid 80:20 (wt:wt) solvent system generates a robust electrospinning system, where only the applied voltage shows statistical significance.
\end{abstract} Res 29(3)-2020. BJSTR. MS.ID.004795.
Keywords: PET;Polymer Fiber;Electrospinning;Scaffold; Box-Behnken

\section{Introduction}

Polyethylene terephthalate (PET) is a semi crystalline polymer, that is used in a variety of applications due to its resistant to environmental effects and good mechanical properties[1,2]. PET is used in the automotive and packaging industry extensively, however lately PET nanofiber mats were used for filtration[3], protective clothing[4], biomedical applications such as tissue engineering scaffolds[5], electroconductive cardiac patch[6] and others[7]. Electrospinning has become a readily used process to generate polymer fibers with average diameters in the nanometer range[8]. Polymer fiber mats generated by electrospinning offer a high surface-to-volume ratio and high porosity[7]. The solution electrospinning process has been discussed in detail in the literature. Briefly, a polymer solution is placed into a container, typically a syringe, that is connected to a needle. The needle is connected to the positive potential outlet of a high voltage DC power supply and the collector is grounded and placed at a desired distance from the needle. The so-called Taylor cone forms at the end of the needle and the solution becomes positively charged[9].
When the tension due to the repulsion forces of the positive charges exceed the surface tension of the solution a jet forms that travels to the collector. During the travel most of the solvent evaporates and a solid polymer fiber deposits on the collector[7,8].

To generate PET fiber mats trifluoroacetic acid (TFA) alone or its mixture with dichloromethane (DCM) is used[10-12]. TFA is a potent acid, $\mathrm{pKa}=0.23$, thus its use for generating PET fibers has its inherent dangers, and it corrodes the equipment $[13,14]$. The aim of this work is to determine the minimum amount of TFA needed to dissolve PET and to produce fibers by electrospinning.

\section{Materials and Methods}

\section{Materials}

Trifluoroacetic acid (Sigma Aldrich, 99\%), dichloromethane (Supelco, ACS grade) and acetone (Supelco, ACS grade) were used as received without any purification. Polyethylene terephthalate (PET) was obtained from a water bottle, that was cleaned with acetone before the solution preparation. 


\section{Electrospinning}

$10 \mathrm{wt} \%$ PET solution was used for electrospinning base on our findings in an earlier work[10]. The TFA:DCM solvent ratios were prepared as indicated. PET fibers were generated on a custombuilt electrospinning device. A plastic syringe contained the PET solution was connected to a needle (G22) through PTFE tubing. The needle was connected to the positive high potential outlet of the high voltage DC power supply (Gamma High Voltage Research, USA) whereas the collector was grounded. A syringe pump was used to supply the desired constant flow rate. The electrospinning process parameters were set as shown in (Table 1).

Table 1: Box-Behnken experimental design and resulted PET fiber diameters.

\begin{tabular}{|c|c|c|c|c|}
\hline $\mathbf{N r}$. & $\mathbf{F}(\mathbf{m L} / \mathbf{h})$ & $\mathbf{D}(\mathbf{c m})$ & $\mathbf{V ~ ( k V )}$ & $\mathbf{d ~ ( n m )}$ \\
\hline 1 & 1 & 25 & 25 & $265 \pm 101$ \\
\hline 2 & 1 & 15 & 25 & $397 \pm 232$ \\
\hline 3 & 1.2 & 20 & 35 & $158 \pm 163$ \\
\hline 4 & 0.8 & 25 & 30 & $358 \pm 147$ \\
\hline 5 & 1 & 20 & 30 & $412 \pm 256$ \\
\hline 6 & 0.8 & 20 & 35 & $384 \pm 172$ \\
\hline 7 & 1 & 15 & 35 & $388 \pm 149$ \\
\hline 8 & 0.8 & 20 & 25 & $379 \pm 175$ \\
\hline 9 & 1 & 25 & 35 & $366 \pm 112$ \\
\hline 10 & 1.2 & 25 & 30 & $430 \pm 237$ \\
\hline 11 & 1.2 & 20 & 25 & $342 \pm 151$ \\
\hline 12 & 0.8 & 15 & 30 & $481 \pm 278$ \\
\hline 13 & 1.2 & 15 & 30 & $483 \pm 234$ \\
\hline 14 & 1 & 20 & 30 & $415 \pm 166$ \\
\hline 15 & 1 & 20 & 30 & $465 \pm 246$ \\
\hline
\end{tabular}

\section{Scanning Electron Microscopy (SEM)}

SEM imaging was performed on a JOEL JSM-5200 scanning electron microscope at $10 \mathrm{kV}$ accelerating potential. The samples were examined as is, without sputter coating. ImageJ software was used to determine the fiber diameter, based on at least 60 measurements for each sample. The measurements were collected from three different x10000 SEM image for each sample.

\section{Results and Discussion}

The aim of this work was to minimize the use of TFA when preparing PET fibers via the electrospinning method. In order to do this several solvent ratios were prepared that are presented in (Table 2).The results show that PET can be dissolved when using only $3 \mathrm{wt} \%$ TFA, however preliminary electrospinning experiments indicated that at DCM:TFA 97:3 solvent ratio the fiber formation process did not start, thus PET fibers could not be obtained. At DCM:TFA 90:10 solvent ratio using $\mathrm{D}=10 \mathrm{~cm}$ collector-to-needle distance, $\mathrm{F}=1 \mathrm{~mL} / \mathrm{h}$ flow rate and $\mathrm{V}=20 \mathrm{kV}$ potential difference PET fibers formed. During the process white, visible PET fibers formed between the tip of the needle and the collector. This is an undesired phenomenon that is most probably due the high evaporation rate of DCM, since we did not observe this earlier, when only TFA was used as solvent[10]. Using DCM:TFA 80:20 solvent ratio to solubilize PET resulted a stable electrospinning process, and the above-mentioned premature fiber solidification did not occur. In order to investigate the flow rate $(F)$, collector-to-needle distance (D) and the applied voltage $(\mathrm{V})$ electrospinning process parameters on the resulting fiber diameter the Box-Behnken method was utilized.

Table 2: Prepared solvent ratios.

\begin{tabular}{|c|c|c|}
\hline Nr. & DCM: TFA (wt\%: $\mathbf{w t} \%)$ & PET solubility \\
\hline 1 & $99: 1$ & No \\
\hline 2 & $97: 3$ & Yes \\
\hline 3 & $95: 5$ & Yes \\
\hline 4 & $90: 10$ & Yes \\
\hline 5 & $80: 20$ & Yes \\
\hline
\end{tabular}

The boundary limits were determined by scoutingexperiments to be $0.8 \mathrm{~mL} / \mathrm{h}$ and $1.2 \mathrm{~mL} / \mathrm{h}$ as the lower and upper limits respectively for the $\mathrm{F}, 15 \mathrm{~cm}$ and $25 \mathrm{~cm}$ for $\mathrm{D}$, and $25 \mathrm{kV}$ and 35 $\mathrm{kV}$ for $\mathrm{V}$. (Table 2)shows the average fiber diameter (d) and the standard deviation corresponding to the applied processing parameters. The produced average fiber diameters vary between $150 \mathrm{~nm}$ and $500 \mathrm{~nm}$. It has to be mentioned that the standard deviations are relatively large, indicating that the fiber diameters are not uniform. The electrospinning process was stable under all investigated conditions and resulted in randomly oriented, well defined, and smooth surfaced PET fibers as it is illustrated in (Figure 1). The SEM images show the presence of beads under all conditions. This could be due to the low viscosity of the solution. Further investigation to eliminate the bead formation by the increase of the solution concentration is needed.The evaluation of the Box-Behnken experimental design ( $R 2=0.7418$, $R 2$ (adj)= 0.2771 ) show statistical significance only in the case of the applied voltage under the examined boundary limits.
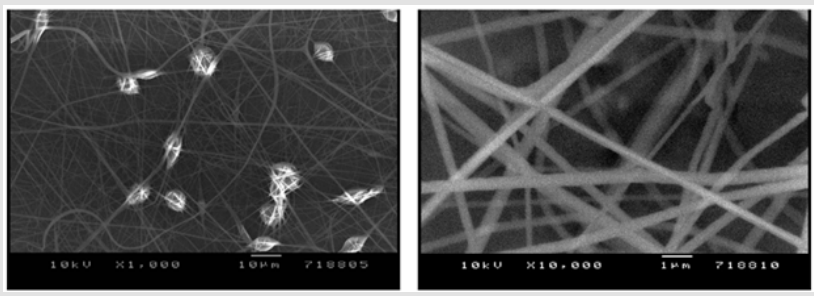

Figure 1: SEM images of sample 9:

a) $\quad$ x1000 and

b) x10000 magnification.

\section{Conclusions}

In conclusion, it can be said that the TFA amount need to produce PET fibers by solution electrospinning was minimized. The results show that at DCM:TFA 97:3 (wt:wt) solvent mixture PET dissolves, however in order to produce fibers DCM:TFA 80:20 
(wt:wt) solvent ratio is needed. Randomly oriented and smoothsurfaced PET fibers were produced with average diameters ranging from $150 \mathrm{~nm}$ to $500 \mathrm{~nm}$. The Box-Behnken experimental design analysis shows statistical significance only in the case of the applied voltage, meaning that the PET electrospinning process using DCM:TFA 80:20 solvent system is robust and only the applied voltage could influence the fiber diameters.

\section{Acknowledgements}

The author wishes to thank the financial support for the Transylvanian Museum Society.

\section{References}

1. Awaja F, Pavel D (2005) Recycling of PET. Eur Polym J 41: 1453-1477.

2. RAJABINEZHAD H, Khajavi R, Rashidi A, Mansouri N, Yazdanshenas ME (2009) Recycling of used bottle grade polyethylene terephthalate to nanofibers by melt-electrospinning method. International Journal of Environmental Research 3(4): 663-670.

3. Strain IN, Wu Q Pourrahimi AM, Hedenqvist MS, Olsson RT, et al. (2015) Electrospinning of recycled PET to generate tough mesomorphic fibre membranes for smoke filtration. J Mater Chem A 3: 1632-1640.

4. Baji A, Agarwal K, Oopath SV (2020) Emerging Developments in the Use of Electrospun Fibers and Membranes for Protective Clothing Applications. Polymers (Basel) 12: 492.

5. Ma Z, Kotaki M, Yong T, He W, Ramakrishna S (2005) Surface engineering of electrospun polyethylene terephthalate (PET) nanofibers

ISSN: 2574-1241

DOI: $10.26717 /$ BJSTR.2020.29.004795

Attila Gergely. Biomed J Sci \& Tech Res

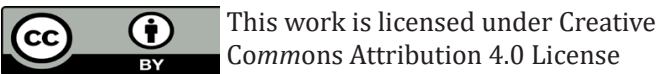

Submission Link: https://biomedres.us/submit-manuscript.php towards development of a new material for blood vessel engineering. Biomaterials 26: 2527-2536.

6. Ghasemi A, Imani R, Yousefzadeh M, Bonakdar S, Solouk A, et al. (2019) Studying the potential application of electrospun polyethylene terephthalate/graphene oxide nanofibers as electroconductive cardiac patch. Macromol Mater Eng 304: 1900187.

7. Huang ZM, Zhang YZ, Kotaki M, Ramakrishna S (2003) A review on polymer nanofibers by electrospinning and their applications in nanocomposites. Compos Sci Technol 63: 2223-2253.

8. Reneker DH, Yarin AL (2008) Electrospinning jets and polymer nanofibers. Polymer (Guildf) 49: 2387-2425.

9. Taylor GI (1969) Electrically driven jets. Proc R Soc London a Math Phys Sci 313: 453-475

10. Gergely A, Kántor J, Bitay E, Biró D (2019) Electrospinning of Polymer Fibres Using Recycled PET. Acta Mater Transylvanica 2: 19-26.

11. Mahalingam S, Raimi Abraham BT, Craig DQM, Edirisinghe M (2015) Solubility--spinnability map and model for the preparation of fibres of polyethylene (terephthalate) using gyration and pressure. Chem Eng J 280: 344-353.

12. Veleirinho B, Rei MF, Lopes DA, Silva JA (2008) Solvent and concentration effects on the properties of electrospun poly (ethylene terephthalate) nanofiber mats. J Polym Sci Part B Polym Phys 46: 460-471.

13. Solomon KR, Velders GJM, Wilson SR, Madronich S, Longstreth J, et al. (2016) Sources, fates, toxicity, and risks of trifluoroacetic acid and its salts: Relevance to substances regulated under the Montreal and Kyoto Protocols. J Toxicol Environ Heal Part B 19: 289-304.

14. Eidman KF, Nichols PJ (2001) Trifluoroacetic acid. Encycl Reagents Org Synth.

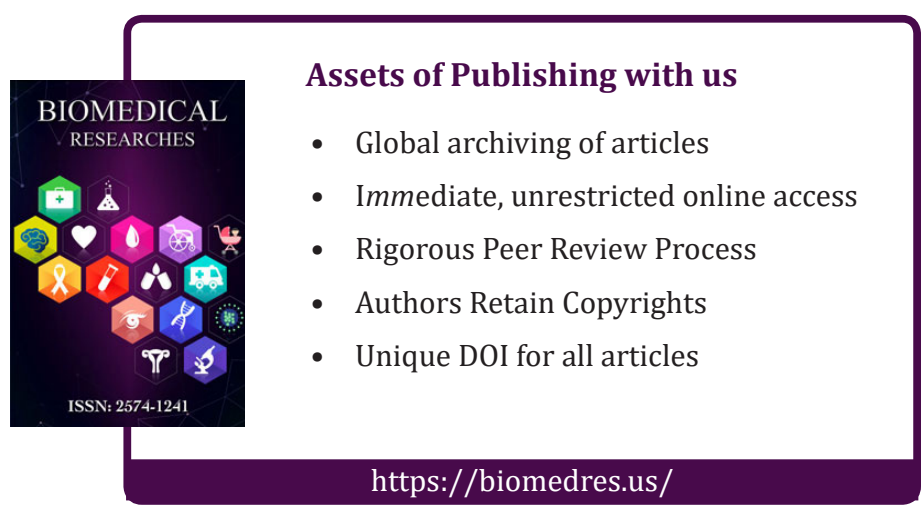

